\title{
The effect of excitation intensity variation and silver nanoparticle codoping on nonlinear optical properties of mixed tellurite and zinc oxide glass doped with $\mathrm{Nd}_{2} \mathrm{O}_{3}$ studied through ultrafast z-scan spectroscopy
}

\author{
L. Moreira ${ }^{a}$, R.F. Falci ${ }^{\text {a }}$, H. Darabian ${ }^{\text {a }}$, V. Anjos ${ }^{\text {a }}$, M.J.V. Bell ${ }^{\text {a }}{ }^{*}$, L.R.P. Kassab ${ }^{\text {b }}$, \\ C.D.S. Bordon ${ }^{\text {C }}$, J.L. Doualan ${ }^{\mathrm{d}}$, P. Camy ${ }^{\mathrm{d}}$, R. Moncorgé ${ }^{\mathrm{d}}$ \\ a Laboratório de Espectroscopia de Materiais, Departamento de Física, Universidade Federal de Juiz de Fora, Juiz de Fora-MG, Brazil \\ ${ }^{\mathrm{b}}$ Laboratório de Tecnologia em Materiais Fotônicos e Optoeletrônicos, Faculdade de Tecnologia de São Paulo, CEETEPS/UNESP, São Paulo, Brazil \\ ${ }^{\mathrm{c}}$ Departamento de Engenharia de Sistemas Eletrônicos, Escola Politécnica da USP, São Paulo, SP, Brazil \\ ${ }^{\mathrm{d}}$ Centre de recherche sur les Ions, les Matériaux et la Photonique (CIMAP), UMR, CNRS-CEA-Ensicaen, Universite de Caen, 6 Boulevard Maréchal Juin, F- \\ 14050, Caen, France
}

\section{A R T I C L E I N F O}

\section{Article history:}

Received 22 August 2017

Received in revised form

11 December 2017

Accepted 8 February 2018

Available online 25 April 2018

\section{Keywords:}

z-scan

$\mathrm{Nd}^{3+}$

Nanoparticles

Nonlinear optics

\begin{abstract}
A B S T R A C T
The research on $\mathrm{Nd}^{3+}$ doped new solid-state laser hosts with specific thermo-mechanical and optical properties is very active. $\mathrm{Nd}^{3+}$ doped tellurite glasses are suitable for these applications. They have high linear and nonlinear refraction index, wide transmittance range. The $\mathrm{TeO}_{2}-\mathrm{ZnO}$ (TZO) glass considered in the present work combines all those features and the nonlinear optical properties can be used for the development of Kerr-lens mode-locked sub picosecond lasers. Recently the laser performance of $\mathrm{Nd}^{3+}$ doped TZO glass and was reported and laser slope efficiency of $21 \%$ was observed. We investigate how the intensity variation and the silver nanoparticles codoping affects the nonlinear optical properties of $\mathrm{Nd}^{3+}$ doped TZO glasses. Intensity dependent nonlinear refraction indices coefficients at 750,800 and $850 \mathrm{~nm}$ were observed. The nonlinear optical features were obtained through ultrafast single beam zscan technique with excitations at 750,800 and $850 \mathrm{~nm}$ and are up to two orders of magnitude higher than those reported in the literature.
\end{abstract}

๑) 2018 Elsevier B.V. All rights reserved.

\section{Introduction}

$\mathrm{Nd}^{3+}$ doped laser materials have a wide variety of applications such as short pulse with high peak power laser systems. Thus, they are very attractive and extensively studied. Also, they have a very interesting ensemble of features, namely, easier 4-levels laser operation mode and usually higher gain cross sections if compared to $\mathrm{Yb}^{3+}$ doped laser materials [1]. Even though laser action of $\mathrm{Nd}^{3+}$ has been observed in a many solid media such as Nd:YAG systems, the research on $\mathrm{Nd}^{3+}$ doped new solid-state laser hosts with specific thermo-mechanical and optical properties is very active. This is the case of some Nd doped nonlinear tellurite glasses [2-8]. They have a conjunction of good thermo-mechanical properties, typical

\footnotetext{
* Corresponding author.

E-mail addresses: mjbell@fisica.ufjf.br, mjbell06@gmail.com (M.J.V. Bell).
}

of crystals, and broad-band spectral properties, typical of glasses. Also, a very interesting combination of large nonlinear refraction index ( 25 times larger than that of silica), wide transmittance range [9].

Usually, crystalline laser hosts lead to higher absorption and emission cross sections, while glasses are produced in larger volumes with optimal optical quality at lower cost. In order to minimize the non-radiative multiphonon relaxations and to optimize the quantum efficiency of the ${ }^{4} \mathrm{~F}_{3 / 2} \rightarrow{ }^{4} \mathrm{I}_{11 / 2}$ emission of $\mathrm{Nd}^{3+}$, it is also suitable to work with $\mathrm{Nd}^{3+}$ doped host materials with low contents of $\mathrm{OH}$ impurities. In that sense, laser emission of $\mathrm{Nd}^{3+}$ in glasses has been reported in fluorides [10-12], chalcogenides [13], aluminosilicates [14], germinates [15], and, as just mentioned, in tellurite glasses [2-6]. Among oxi-tellurites, the $\mathrm{TeO}_{2}-\mathrm{ZnO}$ glass which is considered here in the present article combines good mechanical stability, chemical durability, high linear refraction index together with a wide transmission window $(0.4-6 \mu \mathrm{m})$ and a 
high rare-earth solubility $[10,16,17]$. The large linear refraction index (1.97) [18] of this tellurite glass imply large stimulated emission cross-sections, sometimes larger than for phosphate glasses [19]. These glasses also have high nonlinear optical properties, which can be used advantageously for the development of Kerr-lens mode-locked sub picosecond lasers.

These tellurite glasses have been also studied recently for the possibility of using thin films for the fabrication of rib waveguides [20]. The possibility of increasing the luminescent quantum yield of rare-earth ions by codoping $\mathrm{TeO}_{2}-\mathrm{ZnO}$ glasses with silver nanoparticles [21,22] showed that they are potential materials for photonic devices applications. Recently it was demonstrated the reversible memory phenomena in Au-nanoparticles-incorporated $\mathrm{TeO}_{2}-\mathrm{ZnO}$ films [23]. Also, encouraging improvements have been reported regarding the laser performance of a $\mathrm{Nd}^{3+}$ doped TZO (TeO2-ZnO) glass [24,25]. In this work, laser slope efficiency of $21 \%$ was observed. Thermo-optical properties of tellurite glasses codoped with rare Earth ions and metallic nanoparticles have also been reported [26-28].

These results motivated the present study that reports how the incident intensity variation and the silver nanoparticles codoping affects the nonlinear optical properties of $\mathrm{Nd}^{3+}$ doped TZO glasses.

Measurements were carried out with the Z-scan technique. The results displayed high intensity dependent nonlinear refraction indices at the wavelength range of $750-850 \mathrm{~nm}$, at $80 \mathrm{MHz}$ repetition rate and 100 fs pulses.

\section{Experimental details}

Glasses with the composition 85\%TeO2-15\%ZnO (wt.) (TZO) were obtained with the addition of $1 \% \mathrm{Nd}_{2} \mathrm{O}_{3}$ and $1 \% \mathrm{AgNO}_{3}$ (wt.) (TZO:1\%Nd:1\%Ag). Also a sample without $\mathrm{AgNO}_{3}$ (TZO:1\%Nd) was prepared to be used as reference Reagents were melted at $800^{\circ} \mathrm{C}$ in an platinum crucible for $20 \mathrm{~min}$, quenched in a pre-heated brass mold, annealed at $325^{\circ} \mathrm{C}$ for $2 \mathrm{~h}$, and cooled down to room temperature during $2 \mathrm{~h}$ to avoid internal stresses. At the end of the fabrication process, an additional heat treatment was performed for $24 \mathrm{~h}$, to the sample produced with $\mathrm{AgNO}_{3}$ to thermally reduce the $\mathrm{Ag}^{+}$ions to $\mathrm{Ag}^{0}$ and nucleate silver nanoparticles, following the procedure already reported $[21,22]$. Through this procedure it was possible to obtain high quality samples, with even distribution of the dopants within the glass matrix (TZO).

Absorption spectra were measured in a Perkin-Elmer LAMBDA 9 spectrophotometer in wavelength range from 350 to $1000 \mathrm{~nm}$.

A $200 \mathrm{kV}$ transmission electron microscope (TEM) was employed to investigate the presence of nanoparticles in the samples.
The nonlinear optical features were obtained through ultrafast single beam z-scan setup displayed in Fig. 1. The excitation beam is a Mai Tai HP, Ti:Sapphire NIR, $100 \mathrm{fs}, 80 \mathrm{MHz}$ pulsed Gaussian beam linearly polarized. A Glan-Laser linear polarizer (GL5) positioned at the laser output controls the output intensity. Just after the GL5, a lens focuses the excitation beam in the sample posed on a displacement stage. After crossing the sample the beam goes through the aperture that is set either open or partially (50\%) closed depending on the experiment needs - nonlinear refraction demands closed aperture, while nonlinear absorption demands open aperture. Then, the beam crosses a lens that collimates the signal into a silicon detector connected to a computer, by which the data acquisition is performed.

\section{Absorption spectra and TEM imaging}

The UV-VIS-NIR absorption (absorption coefficient) spectrum of the samples, registered between $350 \mathrm{~nm}$ and $950 \mathrm{~nm}$ is shown in Fig. 2. The features corresponding to the main absorption transitions of $\mathrm{Nd}^{3+}$ from ${ }^{4} \mathrm{I}_{9 / 2}$ fundamental level to excited levels ${ }^{4} \mathrm{~F}_{3}$ 2(890 nm), $\quad{ }^{4} \mathrm{~F}_{5 / 2}+{ }^{2} \mathrm{H}_{9 / 2}(808 \mathrm{~nm}), \quad{ }^{4} \mathrm{~F}_{7 / 2}+{ }^{4} \mathrm{~S}_{3 / 2}(750 \mathrm{~nm}), \quad{ }^{4} \mathrm{~F}_{9 /}$ ${ }_{2}(690 \mathrm{~nm}),{ }^{4} \mathrm{G}_{5 / 2}+{ }^{2} \mathrm{G}_{7 / 2}(580 \mathrm{~nm})$ and ${ }^{4} \mathrm{G}_{7 / 2}+{ }^{4} \mathrm{G}_{9 / 2}+{ }^{2} \mathrm{~K}_{13 / 2}$ have been identified and highlighted in the figure. As expected for a glass, the absorption features appear as broad bands. Also it is interesting to notice that the addition of silver nanoparticles (TZO:1\%Nd:1\%Ag) to the initial composition (TZO:1\%Nd) have resulted in a reasonable enhancement of the absorption. This effect may be attributed to the

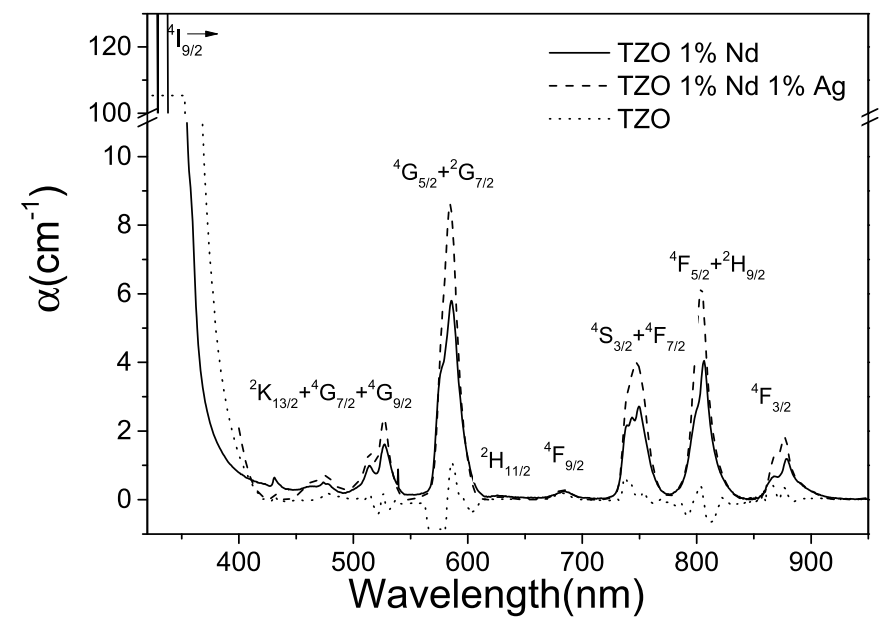

Fig. 2. UV-Vis-NIR absorption spectra for TZO doped and undoped samples.

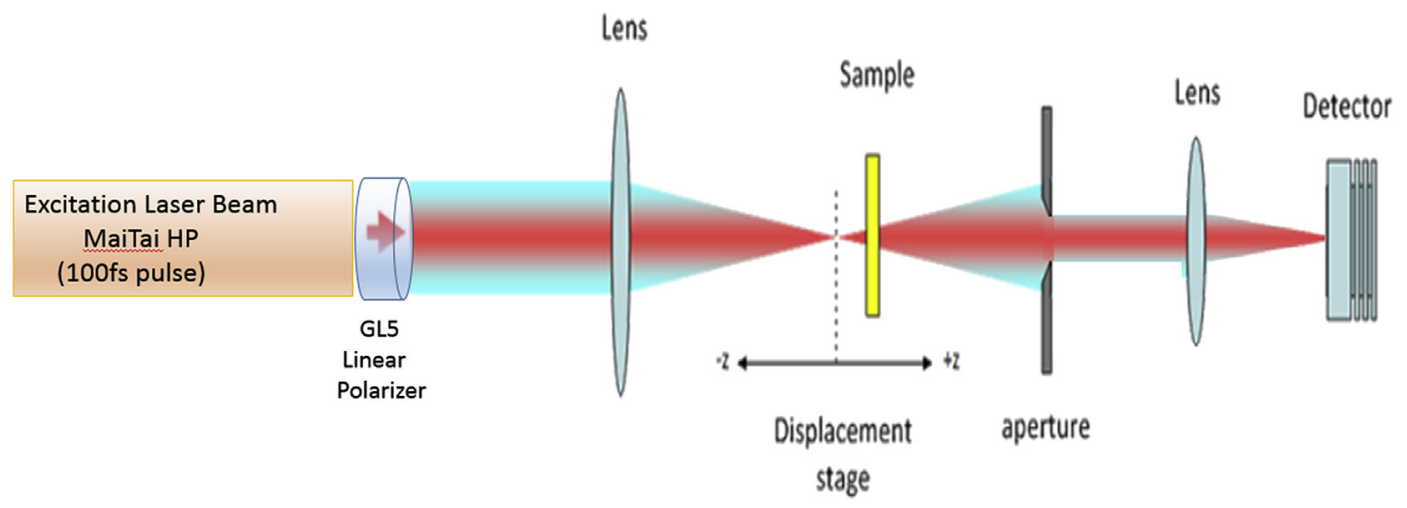

Fig. 1. Z-scan experimental setup [28]. 
Table 1

TZO samples parameters.

\begin{tabular}{llll}
\hline Sample & $\begin{array}{l}\text { Thickness } \\
l(\mathrm{~mm})\end{array}$ & $\begin{array}{l}\text { Linear absorption coefficient } \\
\alpha_{0}\left(\mathrm{~cm}^{-1}\right)\end{array}$ & $\begin{array}{l}\text { Wavelength } \\
(\mathrm{nm})\end{array}$ \\
\hline TZO:1\%Nd & 1,65 & 2,64 & 750 \\
& & 2,61 & 800 \\
& & 0 & 850 \\
TZO:1\%Nd:1\%Ag & 2,98 & 3,91 & 750 \\
& & 4,94 & 800 \\
& & 0 & 850 \\
\hline
\end{tabular}

modification of the $\mathrm{Nd}^{3+}$ ion environment due to the presence of $\mathrm{Ag}$ nanoparticles. 29 Furthermore, when the TZO:1\%Nd and TZO:1\% $\mathrm{Nd}: 1 \%$ Ag samples are compared with the matrix (TZO) it is possible to notice the absence of optical absorption above $500 \mathrm{~nm}$. The linear absorption coefficients $(\alpha)$ correspondent to the chosen excitation wavelength for each sample can be found at Table 1.

Fig. 3 (left) presents TEM images of TZO: $1 \% \mathrm{Nd}: 1 \%$ Ag sample that assures the existence of the silver nanoparticles. We observe isolated silver nanoparticles with average size of $20 \mathrm{~nm}$. Fig. 3 (right) shows the simulated absorption spectra for $20 \mathrm{~nm}$ silver nanoparticles embedded TZO glass, where two resonant plasmons at 425 and $500 \mathrm{~nm}$ are evidenced [30].

\section{Nonlinear refraction}

Nonlinear refraction of the samples was examined with the aid of the z-scan setup depicted on Fig. 1. To evaluate the nonlinear refraction of a transparent medium the aperture should be set partially closed, thus known as closed aperture (C.A.) experiment. Namely, the aperture is set open by $40 \%$, to let only the center of the spot at far field pass to the detector.

Figs. 4-6 display the normalized transmittance for the samples TZO:1\%Nd and TZO:1\%Nd1\%Ag. Since the TZO sample has not shown any optical nonlinear behavior for the wavelengths analyzed here, there is no available data. The experiments were carried for the excitation intensities within the range $0.05-0.45 \mathrm{GW} / \mathrm{cm}^{2}$. No higher intensity was available due to limitations of the system, including the damage limit threshold for the samples TZO:1\%Nd and TZO:1\%Nd1\%Ag. The samples were excited at 750, 800 and $850 \mathrm{~nm}$. The different wavelengths used for excitation and presented in Figs. 4-6 have been based on the nonlinear optical refraction responses detected. The TZO:1\%Nd sample showed higher sensitivity at 750 and $800 \mathrm{~nm}$, whereas TZO:1\%Nd:1\%Ag at 800 and $850 \mathrm{~nm}$. This difference can be attributed to the silver nanoparticles interaction with the matrix TZO.

The 3rd order nonlinear refraction effect could be observed just for the TZO: $1 \% \mathrm{Nd}$ and TZO:1\%Nd1\%Ag samples. Additionally, no relevant nonlinear absorption was observed at any of the tested samples. Thus, the data obtained from these measurements were fitted to the following expression [31,32]:

$\Delta T_{P V} \cong 0,406(1-S)^{0,27}\left|\Delta \Phi_{0}\right|$

$\Delta \Phi_{0}=\left(\frac{2 \pi}{\lambda}\right) Z_{0} I_{0} n_{2} l_{\text {eff }}, \quad l_{\text {eff }}=\frac{1-e^{-\alpha l}}{\alpha}, Z_{0}=\frac{\pi \omega_{0}^{2}}{\lambda}$

where $\Delta T_{P V}=T_{P}-T_{V}$ is the change in transmittance between the peak and valley, and $T_{P}$ and $T_{V}$ are the normalized peak and valley transmittances, $\Delta \Phi_{0}$ is the nonlinear phase with the sample at the focus, $Z_{0}$ is the Rayleigh length, $Z$ the sample position relative to the focus $(Z=0 \mathrm{~mm}), \lambda$ is the excitation laser wavelength, $\mathrm{n}_{2}$ is the $3 \mathrm{rd}$ order nonlinear refraction index and $I_{0}$ is the peak intensity, $\omega_{0}$ is the beam waist at the focus, $S$ is the transmittance of the aperture in the absence of a sample, here $S=0,4$.

Figs. 4-6 show a similar nonlinear behavior of the samples, selffocusing Kerr lenses in all cases studied. The amplitude of the signal denotes the value $\Delta \Phi_{0}$. The TZO:1\%Nd results at $750 \mathrm{~nm}$ (Fig. $6 \mathrm{~A}$ ) and $800 \mathrm{~nm}$ (Fig. 5A), evidence that $\Delta \Phi_{0}$ increases with rise of the excitation intensity, but for $850 \mathrm{~nm}$ (Fig. 4A) the reverse situation is observed. The TZO:1\%Nd1\%Ag sample exhibits the same nonlinear optical behavior for the three excitation wavelengths but with higher amplitudes, indicating that the presence of the silver nanoparticles in the TZO:1\%Nd 1\%Ag enhanced the nonlinear optical features.

The results of the 3rd order nonlinear refraction index $\left(n_{2}\right)$ as function of the excitation intensity, are shown in Fig. 7. It is possible to notice that $n_{2}$ shows an exponential decay behavior with the rise of $I_{0}$. We observe high values for $n_{2}$ that reaches $4 \times 10^{-12} \mathrm{~cm}^{2} / \mathrm{W}$, at $850 \mathrm{~nm}\left(0.05 \mathrm{GW} / \mathrm{cm}^{2}\right)$, for the sample with silver nanoparticles whereas in the absence of silver nanoparticles $n_{2}$ is significantly lower, around $2 \times 10^{-13} \mathrm{~cm}^{2} / \mathrm{W}$. It was observed enhancement of about $50 \%$, in the presence of silver nanoparticles, at $800 \mathrm{~nm}$, for the same excitation intensity $\left(0.3 \mathrm{GW} / \mathrm{cm}^{2}\right)$. Furthermore, a fitting
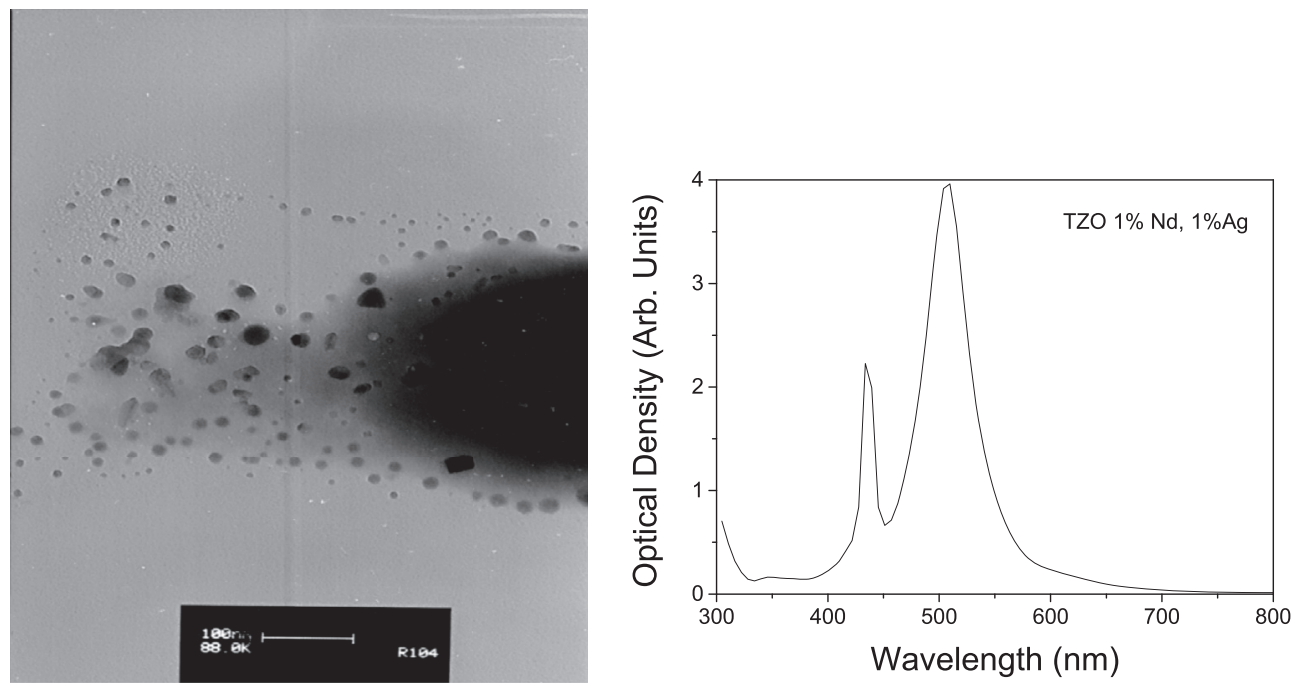

Fig. 3. TEM Image of the TZO:1\%Nd:1\%Ag (left) and the Simulated absorption spectra for $20 \mathrm{~nm}$ Silver Nanoparticles embedded at TZO glass [29](right). 

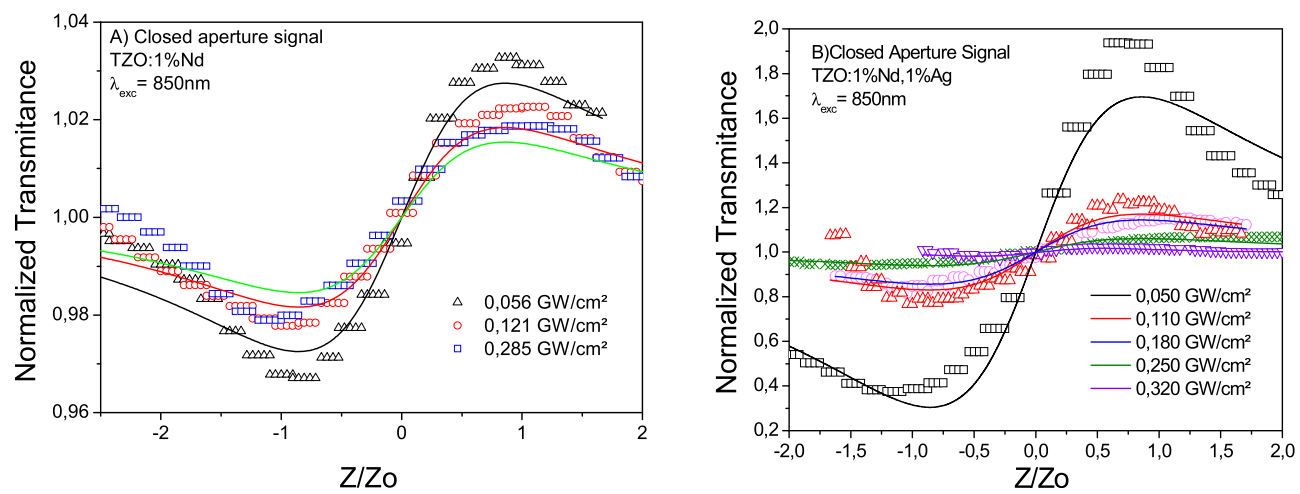

Fig. 4. Closed Aperture (C.A.) Z-scan signal at $850 \mathrm{~nm}$ for different excitation intensities.
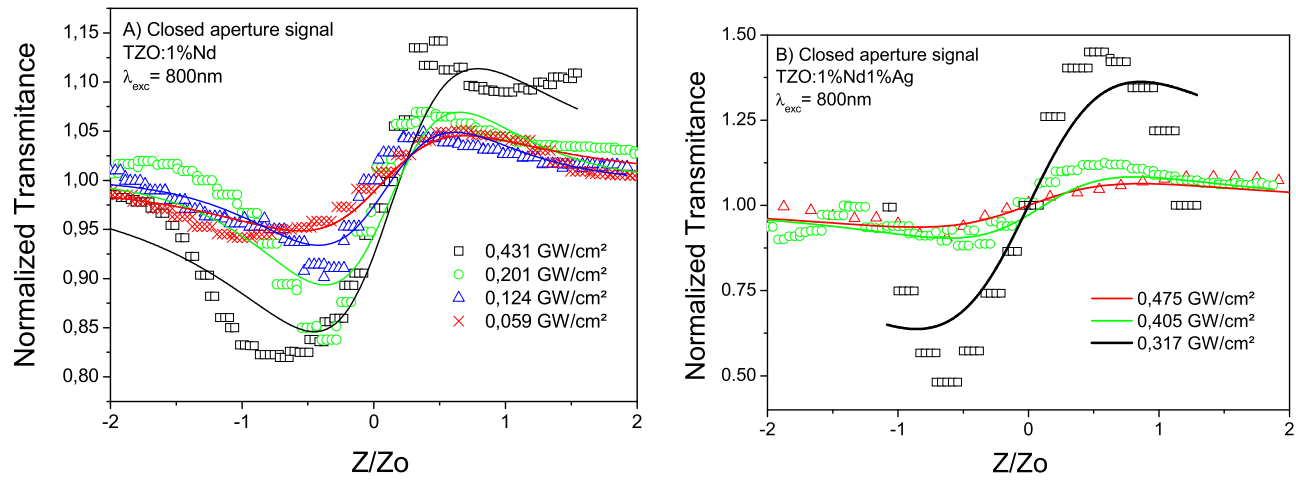

Fig. 5. Closed Aperture (C.A.) Z-scan signals at $800 \mathrm{~nm}$ for different excitation intensities.

was performed using the empirical expression (3) in order to obtain the 3rd order nonlinear refraction indices for high intensity excitation, $n_{2, \infty}$. The results are displayed in Table 2 .

$n_{2}\left(I_{0}\right)=n_{2, I} \exp \left(-I_{0} / I_{n 2}\right)+n_{2, \infty}$

In the equation above $n_{2}\left(I_{0}\right)$ is the 3rd order nonlinear refraction index as function of the excitation intensity $I_{0}, n_{2, I}$ is the amplitude, $I_{n 2}$ is the decay constant and $n_{2, \infty}$ is the 3rd order nonlinear refraction index at high intensity excitation.

Regarding the $n_{2, \infty}$, it is possible to observe a significant rise at $850 \mathrm{~nm}$ with addition of silver nanoparticles. However, for the lower excitation wavelengths, $n_{2, \infty}$ is diminished roughly by half. Even though this result is unexpected, we should consider the fact that the addition of metallic nanoparticles to an emission media, should favor radiative transitions over other energy transfer processes. In fact, $750 \mathrm{~nm}$ and $800 \mathrm{~nm}$ lay among pumping wavelengths for the $\mathrm{Nd}^{3+}$ ion, as can be seen in Fig. 1. Thus it is possible to expect a significant enhancement in emission, when silver nanoparticles are added.

The evolution of the nonlinear indices with the increasing intensity have been observed and discussed before, even if not analyzed mathematically. The behavior of $n_{2}$ variation due to increasing excitation intensities have been reported by A.S. Reyna and C. B. de Araujo [33] and also by R.A.Ganeev et al. [34]. They reported as the most likely reasons for the $n_{2}$ changes due to excitation rise:

(1) Interband transitions taking into account the possibility of two-photon process [34]. This process can be taken into

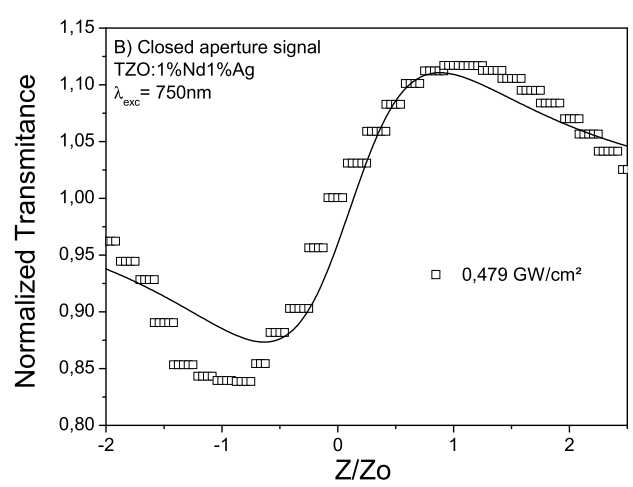

Fig. 6. Closed Aperture (C.A.) Z-scan signals at $750 \mathrm{~nm}$ for different excitation intensities. 

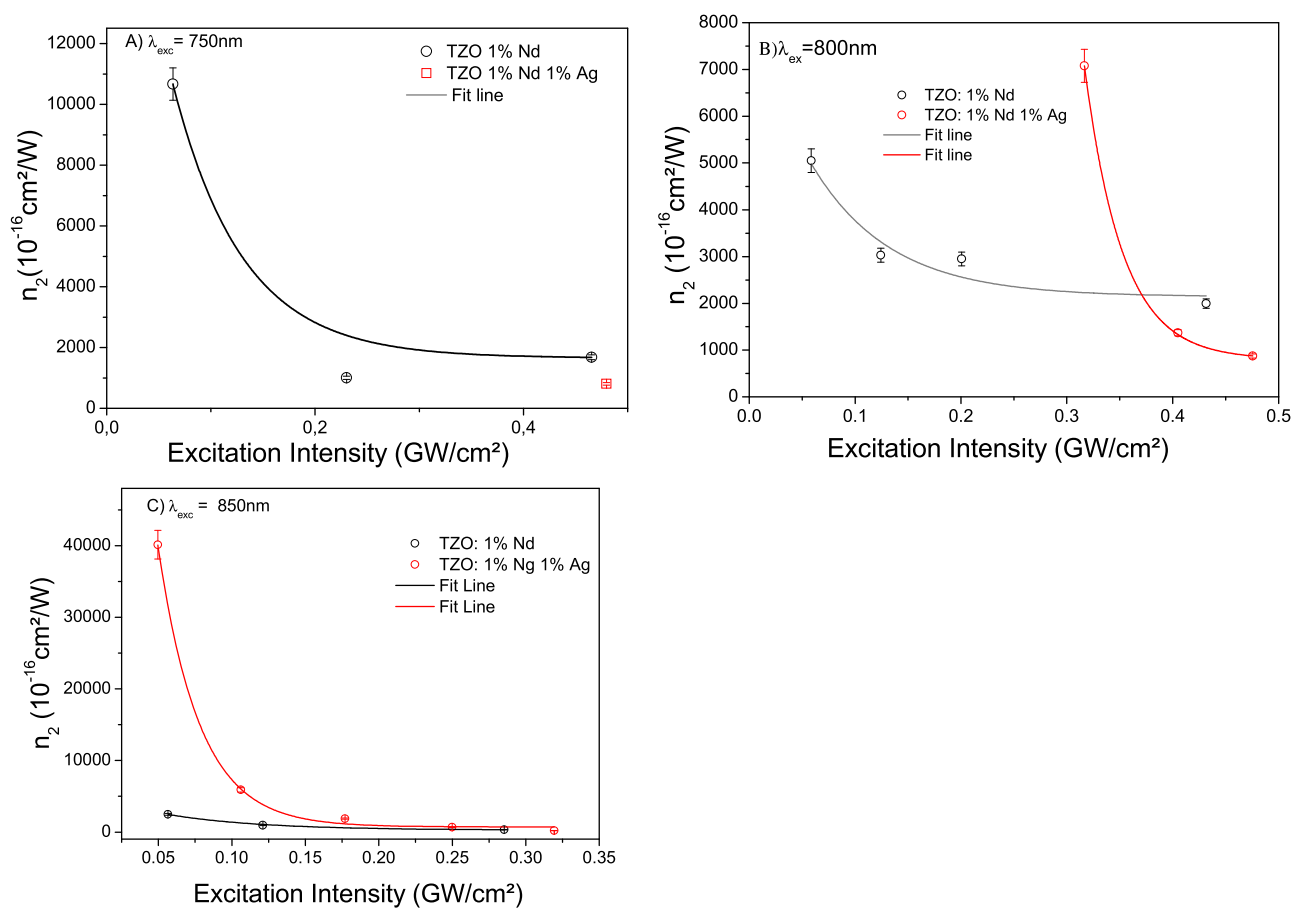

Fig. 7. Nonlinear Refraction Index ( $\left.\mathbf{n}_{\mathbf{2}}\right)$ as Function of the Excitation Intensity at A) $750 \mathrm{~nm}$, B) $\left.800 \mathrm{~nm}, \mathrm{C}\right) 850 \mathrm{~nm}$.

Table 2

TZO nonlinear refraction indices $\left(\mathrm{n}_{2}\right)$ as function of the excitation intensity $\left(\mathrm{I}_{0}\right)$.

\begin{tabular}{|c|c|c|c|c|}
\hline \multicolumn{5}{|c|}{$n_{2}\left(I_{0}\right)=n_{2, I} \exp \left(-I_{0} / I_{n 2}\right)+n_{2, \infty}$} \\
\hline Sample & Wavelength(nm) & $n_{2, \infty}\left(10^{-14} \mathrm{~cm}^{2} / \mathrm{W}\right)$ & $n_{2, I}\left(10^{-13} \mathrm{~cm}^{2} / \mathrm{W}\right)$ & $\mathrm{I}_{\mathrm{n} 2}(\mathrm{GW})$ \\
\hline \multirow[t]{3}{*}{ TZO:Nd } & 750 & 16,584 & 23,356 & 0,067 \\
\hline & 800 & 21,411 & 6275 & 0,045 \\
\hline & 850 & 2655 & 5355 & 0,063 \\
\hline \multirow[t]{3}{*}{ TZO:Nd:Ag } & 750 & 8073 & & \\
\hline & 800 & 8008 & $4.383,840$ & 0,036 \\
\hline & 850 & 7188 & 229,350 & 0,028 \\
\hline
\end{tabular}

consideration for the TZO: $1 \% \mathrm{Nd} 1 \% \mathrm{Ag}$ sample since it has shown resonance plasmon at $425 \mathrm{~nm}$ and was excited at $850 \mathrm{~nm}$.

(2) Thermal effect. Positive contribution to the nonlinear refractive index can be caused by thermal effect, which can be considered as a result of energy transfer from heated dopant to surrounding dielectric matrix. However, the time necessary for this process to be important corresponds to a few nanoseconds, whereas the pulse duration was five orders shorter (100 fs), which diminishes the influence of the thermal effect causing the acoustic-induced variation of density and refractive index of matrix [34].

(3) The irreversible change of $n_{2}$ caused by laser radiation. This effect was analyzed in several studies of composite materials doped with copper and silver nanoparticles. The mechanism responsible for the change was a photochemical reaction, which produced a silver-oxide layer on the surface of nanoclusters. The irreversible changes in both studies were caused by a thermal influence produced by high pulse repetition rate radiation [33]. In our case, the Z-scans had a good reproducibility in time, so the influence of irreversible changes can be easily excluded.

It also possible to evaluate the results of $n_{2}$ for similar materials.
S.K.Mahajan reported $n_{2}=1.21 \times 10^{-15} \mathrm{~cm}^{2} / \mathrm{W}$, at $800 \mathrm{~nm}, 100 \mathrm{fs}$, $80 \mathrm{MHz}$, for a $\mathrm{Er}^{3+}$ doped $\mathrm{TeO}_{2}-\mathrm{Li}_{2} \mathrm{O}-\mathrm{WO}_{3}$ glass [35]. Nonlinear refraction indices of $\mathrm{PbO}-\mathrm{Nb}_{2} \mathrm{O}_{5}-\mathrm{TeO}_{2}$ glasses at $800 \mathrm{~nm}, 90 \mathrm{fs}, 1 \mathrm{kHz}$ were studied recently; nonlinear refraction indices in the range $1.42-1.78 \times 10^{-14} \mathrm{~cm}^{2} / \mathrm{W}$ were obtained for different concentration of $\mathrm{PbO}-\mathrm{Nb}_{2} \mathrm{O}_{5}-\mathrm{TeO}_{2}$. Another interesting result has been obtained by K. Kato [36], who studied the optical nonlinearities of $20 \mathrm{Ag}_{2} \mathrm{O}-80 \mathrm{TeO}_{2}$ glasses, their highest value was $n_{2}=8.75 \times 10^{-15} \mathrm{~cm}^{2} / \mathrm{W}$, at $800 \mathrm{~nm}, 90 \mathrm{fs}, 1 \mathrm{kHz}$.

D.Linda observed the role of silver nanoparticles on nonlinear optical properties at $\mathrm{TeO}_{2}-\mathrm{Ti}_{2} \mathrm{O}-\mathrm{Ag}_{2} \mathrm{O}$ and $\mathrm{TeO}_{2}-\mathrm{ZnO}-\mathrm{Ag}_{2} \mathrm{O}$ ternary systems [37]. The silver nanoparticles increased the energy transfer among the ions that build the matrix generating enhancement of $n_{2}$ ranging from 28 to $40 \times 10^{-14} \mathrm{~cm}^{2} / \mathrm{W}$ at $800 \mathrm{~nm}, 90 \mathrm{fs}, 1 \mathrm{KHz}$. Goméz observed the nonlinearities of silver nanoparticles in colloidal media, and obtained $n_{2}$ around $10^{-15} \mathrm{~cm}^{2} / \mathrm{W}(533 \mathrm{~nm}, 8 \mathrm{~ns}, 10 \mathrm{~Hz})$ and linear absorption peak around $500 \mathrm{~nm} \mathrm{[38].} \mathrm{In} \mathrm{the} \mathrm{present} \mathrm{study} \mathrm{we} \mathrm{have} \mathrm{added} 20 \mathrm{~nm}$ silver nanoparticles to the original composition of TZO: $1 \% \mathrm{Nd}$. Through simulation [29] it was possible to obtain the nanoparticles absorption spectrum embedded in TZO: $1 \% \mathrm{Nd}$ medium, available at Fig. 6. We can observe two peaks, around $425 \mathrm{~nm}$ and $500 \mathrm{~nm}$. This would justify the enhanced sensibility at $850 \mathrm{~nm}$, for the sample prepared with silver nanoparticles. 
Then comparing the results recently reported we conclude that the samples presented in this work have nonlinear refraction indices that are at the same order or up to two orders of magnitude higher than those reported to tellurite glasses in the $750-850 \mathrm{~nm}$ range.

\section{Conclusion}

The nonlinear optical properties of $\mathrm{Nd}^{3+}$ doped TZO glasses with and without silver nanoparticles is studied. The nonlinear optical features were obtained through ultrafast single beam z-scan technique. The samples were excited at 750,800 and $850 \mathrm{~nm}$. The 3rd order nonlinear refraction index $\left(\mathrm{n}_{2}\right)$ shows an exponential decay behavior with the rise of the excitation intensity. Then it reaches a constant value at high intensity values. In comparison to the glasses available in the literature, the samples presented in this work have nonlinear refraction indices that at the same order or up to two orders of magnitude higher than those reported to tellurite glasses in the $750-850 \mathrm{~nm}$ range. The enhanced nonlinear refraction index due to the increased local field that surrounds the silver nanoparticles could be observed. The high nonlinear properties of the samples presented here make them good candidates for subpico Kerr effect based lasers. Likewise, they demand further examinations such as recovery time and damage threshold to better define the potential for possible applications.

\section{Acknowledgments}

The authors acknowledge the financial support of the Brazilian agencies CAPES, FAPEMIG, National Institute of Photonics (INCT Project/CNPq), CAPES/COFECUB, and CNPq.

\section{References}

[1] Solid-State Lasers/Nd lasersF. Träger (Ed.), Handbook of Lasers and Optics, Springer, New-York, 2007, pp. 636-648.

[2] J.C. Michel, D. Morin, F. Auzel, Propriétés spectroscopiques et effet laser d'un verre tellurite et d'un verre phosphate dopés en néodyme, Rev. Phys. Appl. 13 (1978) 859.

[3] A. Miguel, J. Azkargorta, R. Morea, I. Iparraguirre, J. Gonzalo, J. Fermamdez, R. Balda, Spectral study of the stimulated emission of $\mathrm{Nd} 3+$ in fluorotellurite bulk glass, Opt. Expr. 21 (2013), 009298.

[4] H. Kalaycioglu, H. Cankaya, G. Ozen, L. Ovecoglu, A. Sennaroglu, Lasing at 1065 $\mathrm{nm}$ in bulk Nd3+-doped telluride-tungstate glass, Opt. Commun. 281 (24) (2008) 6056-6060.

[5] I. Iparraguirre, J. Azkargorta, J.M. Fernández-Navarro, M. Al-Saleh, J. Fernández, R. Balda, Laser action and upconversion of Nd3+ in tellurite bulk glass, J. Non Cryst. Solids 353 (8-10) (2007) 990-992.

[6] N. Lei, B. Xu, Z.H. Jiang, Ti-sapphire laser pumped Nd-tellurite glass laser, Opt. Commun. 127 (4-6) (1996) 263-265.

[7] W. Ryba-Romanowski, S. Golab, L. Cichosz, B.J. Ttzebiatowska, Influence of temperature and acceptor concentration on energy transfer from $\mathrm{Nd} 3+$ to Yb3+ and from Yb3+ to Er3+ in tellurite glass, J. Non Cryst. Solids 105 (295) (1988) 15.

[8] J.S. Wang, E.M. Vogel, E. Snitzer, J.L. Jackel, V.L. da Silva, Y. Silberberg, $1.3 \mu \mathrm{m}$ emission of neodymium and praseodymium in tellurite-based glasses, J. Non Cryst. Solids 178 (1994) 109.

[9] R.A.H. El-Mallawany, Tellurite Glasses Handbook-physical Properties and Data, CRC, Boca Raton, FL, 2001.

[10] R.R. Petrin, M.L. Kliewer, J.T. Beasley, R.C. Powell, I.D. Aggarwal, R.C. Ginther, Spectroscopy and laser operation of Nd:ZBAN glass, IEEE J. Quant. Electron. 27 (4) (1991) 1031-1038.

[11] J. Azkargorta, I. Iparraguirre, R. Balda, J. Fernández, E. Dénoue, J.L. Adam,
Spectroscopic and laser properties of Nd3+ in BIGaZLuTMn fluoride glass, IEEE J. Quant. Electron. 30 (8) (1994) 1862-1867.

[12] J. Azkargorta, I. Iparraguirre, R. Balda, J. Fernández, On the origin of bichromatic laser emission in Nd3+-doped fluoride glasses, Opt. Expr. 16 (16) (2008) 11894-11906.

[13] T. Schweizer, D.W. Hewak, D.N. Payne, T. Jensen, G. Huber, Rare-earthdoped chalcogenide glass laser, Electron. Lett. 32 (7) (1996) 666-667.

[14] D.F. de Sousa, L.A.O. Nunes, J.H. Rohling, M.L. Baesso, Laser emission at 1077 $\mathrm{nm}$ in Nd3+-doped calcium aluminosilicate glass, Appl. Phys. B 77 (2003) 59-63.

[15] J. Fernandez, I. Iparraguirre, R. Balda, J. Azkargorta, M. Voda, J.M. FernandezNavarro, Laser action and upconversion of $\mathrm{Nd} 3+$ in lead-niobium-germanate bulk glass, Opt. Mater. 25 (2) (2004) 185-191.

[16] J.S. Wang, E.M. Vogel, E. Snitzer, Tellurite glass: a new candidate for fiber devices, Opt. Mater. 3 (3) (1994) 187-203.

[17] A. Jha, S. Shen, M. Naftaly, Structural origin of spectral broadening of $1.5-\mu \mathrm{m}$ emission in Er3+ doped tellurite glasses, Phys. Rev. B 62 (10) (2000) 6215-6227.

[18] H.A.A. Sidek, S. Rosmawati, Z.A. Talib, M.K. Halimah, W.M. Daud, Synthesis and optical properties of ZnO-TeO2 glass system, Am. J. Appl. Sci. 6 (8) (2009) 1489-1494.

[19] M.J. Weber, Science and technology of laser glass, J. Non Cryst. Solids 123 $(1-3)(1990) 208-222$

[20] V.D. Del Cacho, A.L. Siarkowsi, N. Morimoto, H.V. Borges, L.R.P. Kassab, Fabrication and characterization of TeO2-ZnO rib waveguides, ECS Trans. 31 (1) (2010) 219.

[21] L.R.P. Kassab, L.F. Freitas, T.A.A. de Assumpção, D.M. da Silva, C.B. de Araújo, Frequency upconversion properties of Ag: TeO2-ZnO nanocomposites codoped with Yb3+ and Tm3+ ions, Appl. Phys. B 104 (2011) 1029.

[22] T.A.A. de Assumpção, M.E. Camilo, L.R.P. Kassab, A.S.L. Gomes, C.B. de Araújo, N.U. Wetter, Frequency upconversion properties of Tm3 + doped $\mathrm{TeO} 2-\mathrm{ZnO}$ glasses containing silver nanoparticles, J. Alloys Compd. 536 (2012) S504-S506.

[23] L. Bontempo, S.G. dos Santos Filho, L.R.P. Kassab, Thin Solid Films 611 (2016) $21-26$.

[24] M.J.V. Bell, V. Anjos, L.M. Moreira, R.F. Falci, L.R.P. Kassab, D.S. da Silva, J.L. Doualan, P. Camy, R. Moncorgé, Laser emission of a Nd-doped mixed tellurite and zinc oxide glass, J. Opt. Soc. Am. B 31 (7) (July 2014) 1590-1594.

[25] M.J.V. Bell, V. Anjos, L.M. Moreira, R.F. Falci, L.R.P. Kassab, D.S. da Silva, J.L. Doualan, P. Camy, R. Moncorgé, The effects of $\mathrm{Nd}_{2} \mathrm{O}_{3}$ concentration in the laser emission of $\mathrm{TeO}_{2}-\mathrm{ZnO}$ glasses, Opt. Mater. 58 (2016) 84-88.

[26] A.P. Carmo, M.J.V. Bell, V. Anjos, R. De Almeida, D.M. Da Silva, L.R.P. Kassab, Thermo-optical properties of tellurite glasses doped with Eu3+ and Au nanoparticles, J. Phys. D Appl. Phys. 42 (2011), 155404.

[27] A.P. Silva, A.P. Carmo, V. Anjos, M.J.V. Bell, L.R.P. Kassab, R. de Almeida Pinto, Temperature coefficient of optical path of tellurite glasses doped with gold nanoparticles, Opt. Mater. 34 (1) (2009) 239-243.

[28] E.A. Carvalho, A.P. Carmo, M.J.V. Bell, V. Anjos, L.R.P. Kassab, D.M. da Silva, Optical and thermal investigation of $\mathrm{GeO} 2-\mathrm{PbO}$ thin films doped with $\mathrm{Au}$ and Ag nanoparticles, Thin Solid Films 520 (7) (2012) 2667-2671.

[29] Asmahani Awang, S.K. Ghoshal, M.R. Sahar, R. Arifin, Gold nanoparticles assisted structural and spectroscopic modification in Er3+-doped zinc sodium tellurite glass, Opt. Mater. 42 (2015) 495-505.

[30] Jon Camden, George C. Schatz, Nanosphere Optics Lab, 2016, https://doi.org/ 10.4231/D30814T3N. https://nanohub.org/resources/nsoptics.

[31] M. Sheik-Bahae, et al., IEEE J. Quant. Electron. 26 (1990) 760.

[32] E.W. Van Stryland, M. Sheik-Bahae, in: M.G. Kuzyk, C.W. Dirk (Eds.), Characterization Techniques and Tabulations for Organic Nonlinear Materials, Marcel Dekker, Inc., 1998, pp. 655-692.

[33] A.S. Reyna, C.B. De Araujo, High-order optical nonlinearities in plasmonic nanocomposites-a review", Adv. Opt. Photon 9 (4) (December 2017).

[34] R.A. Ganeev, et al., Saturated absorption and nonlinear refraction of silicate glasses doped with silver nanoparticles at $532 \mathrm{~nm}$, Opt. Quant. Electron. 36 (2004) 949-960. Kluwer Academic Publishers. Printed in the Netherlands.

[35] Raouf A.H. El-Mallawan, Tellurite Glasses Handbook: Physical Properties and Data, second ed., CRC Press, 2016, p. 148.

[36] K. Kato, T. Hayakawa, Y. Kasuya, P. Thomas, J. Non Cryst. Solids 431 (2016) 97.

[37] D. Linda, et al., Optical properties of tellurite glasses elaborated within the TeO2-Tl2O-Ag2O and TeO2-ZnO-Ag2O ternary systems, J Alloys Compd. 561 (2013) 151-160.

[38] Goméz, et al., Influence of stabilizing agents on the nonlinear susceptibility of silver nanoparticles, J. Opt. Soc. Am. B 24 (9) (September 2007). 